\title{
REVIEW
}

\section{Deficiencies of Traditional Grading Systems and Recommendations for the Future}

\author{
Jeff Cain, EdD, MS ${ }^{\mathrm{a}}$, Melissa Medina, EdD ${ }^{\mathrm{b}}$, Frank Romanelli ${ }^{\mathrm{a}}$, Adam Persky, $\mathrm{PhD}^{\mathrm{c}}$ \\ ${ }^{\text {a }}$ University of Kentucky, College of Pharmacy, Lexington, Kentucky \\ ${ }^{\mathrm{b}}$ University of Oklahoma, College of Pharmacy, Oklahoma City, Oklahoma \\ ${ }^{\mathrm{c}}$ University of North Carolina at Chapel Hill, Chapel Hill, North Carolina
}

Corresponding Author: Jeff Cain, University of Kentucky, College of Pharmacy, 789 South Limestone Dr., Lexington, KY 405360596. Tel: 859-257-4429. Email: jeff.cain@uky.edu

Submitted August 17, 2021; accepted November 15, 2021; ePublished December 2021

\begin{abstract}
Objective. To review the issues surrounding the use of grades in the educational process and provide evidence-based recommendations for how to re-design grading practices for optimal value.

Findings. Traditional, multi-tiered grading systems (ie, A, B, C, etc.) have historically been a major component of the formal educational process. The way grades are used and interpreted are typically based on some commonly held assumptions including that they are accurate measures of learning, that they motivate students to learn, and that they provide feedback to learners. However, much of the research regarding grades indicates that there are flaws in these assumptions. Grades may not always accurately measure learning, they can have adverse effects on student motivation, and they are not a good form of feedback.

Summary. The Academy should consider the evidence regarding the purpose, effects, and interpretation of grades in the educational process. Despite barriers and potential pushback, pharmacy educators should revise grading practices to be more accurate, interpretable, and beneficial to learner development.
\end{abstract}

Keywords: grades, assessment, motivation, feedback

\section{INTRODUCTION}

Grades are deeply embedded within educational systems, providing teachers, students, and others a simple way to quantify and interpret the complex and nuanced aspects of learning. We use them to measure learning, sort students, motivate learning behaviors, and provide feedback, yet some educators have begun to question the validity of traditional practices including how grades are determined and their effects on learner behavior. ${ }^{1}$ Alternative forms of grading, such as competency-based assessment ${ }^{2}$, specifications grading ${ }^{3}$, and "un-grading" ${ }^{4}$ have become more popular recently as educators have begun to realize the downsides of traditional grading systems. As discussions of grading reforms spread throughout health professions education, it is important to understand the associated issues and concerns with contemporary grading practices. The literature regarding grades and associated assessment practices is interwoven and expansive, making it difficult for educators to understand the depth and breadth of issues. This review provides an overview of theories and practices surrounding grades, current limitations of traditional grading systems, and barriers to change. We conclude with recommendations for how colleges/schools of pharmacy and instructors can re-design grading practices to improve both student performance and accuracy of learning measurement.

\section{A Brief History}

Grades were first instituted in the 1700s in Europe to foster competition among students for prizes and rank order. In the late 1700s Yale University introduced achievement-based rankings and classifications, and by 1800 paved the way for a 4.0 grade point average scale. ${ }^{5}$ By the mid to late $1800 \mathrm{~s}$, Harvard University, University of Michigan, and Mount Holyoke College all had adopted a letter grading system with passing rates set arbitrarily as $26 \%, 50 \%$ and $75 \%$, respectively. Eventually, in this tiered grading system an A came to mean students earned $90 \%$ of total possible points, a $\mathrm{B}$ in the $80 \mathrm{~s}$, a $\mathrm{C}$ in the $70 \mathrm{~s}$ and an $\mathrm{F}$ below $60 \% .{ }^{5}$ Along with the quantifiers were qualifiers with an $\mathrm{A}$ indicating an exceptional level of achievement, a $\mathrm{B}$ good but not outstanding and a $\mathrm{C}$ a fair level. Over time, however, these meanings have eroded and the uses and purposes of grades have changed, introducing challenges to the teaching and learning process. ${ }^{3}$ Because there are significant global variations in how grades are structured and assigned, this review focuses on traditional grading schemes within the United States, although the same issues and concerns are relevant throughout other educational systems. 


\section{Does the Traditional Grading System Accurately Measure Learning?}

The most basic assumption concerning grades is that they accurately measure learning. However, numerous factors influence the validity of traditional grades in measuring learning and how those measurements are interpreted.

First, the precision of how we measure and report learning (through points and grades) depends on the reliability of our assessments. Figure 1 illustrates how differences in Kuder-Richardson (KR-20) scores of assessments and standard deviations can cloud the interpretations of learning differences between a ' $\mathrm{B}$ ' student and a ' $\mathrm{C}$ ' student. If the assessment has a Kuder-Richardson Formula 20 (KR-20) of 0.9, which is excellent, then it is reasonable to assume their true score would reflect actual learning. If we assume a standard deviation of $10 \%$ then there is no overlap between the distributions of the true score $(\mathrm{X} \pm \mathrm{SEM})$ and we may be confident we can differentiate between the two students. However, if our KR20 drops to .6 with the same $10 \%$ standard deviation, there now is overlap between the two true score distributions. The situation is further complicated as the standard deviation increases, preventing us from definitively stating that the B student has learned more than the $\mathrm{C}$ student.

Second, if grades are comprised of items other than assessment of knowledge and skills, then they may not accurately reflect learning. When points are awarded for subjective activities that aid the learning process (eg, participation or homework completion), results will vary from when we only consider objective measures of standards achievement (ie, quizzes and exams). Table 1 illustrates these variations through an example of three students with varying performance and different grading schemes.

Third, when assessing via exams, the number of questions that differentiate a grade is also important. For example, the difference between a student with an $80 \%$ versus $70 \%$ on a 10 -question assessment, is only a 1 question difference ( $8 / 10 \mathrm{vs} 7 / 10)$. The issue then, is a single question sufficient to discern an above average (80\%) student from an average student $(70 \%)$ ? With a 100 -question exam, the difference between average and above average is 10 questions. Whether those 10 questions relate to a single competency or four different competencies may also change an instructor's interpretation of what the grade means.

Fourth, there can be considerable variability among instructors in their criteria for achieving high grades. Differences in grading rigor and leniency among instructors are well-documented. ${ }^{7}$ For that reason, it is easy to comprehend how instructor variability complicates the interpretation of what grades really mean. Also, beginning in K-12 education, subjects such as social studies focus on performance and tests, while mathematics and English focus on enablers like effort, class participation, and homework. ${ }^{8}$ If K-12 educators formally trained in assessment exhibit variability in grading, it is reasonable to assume that pharmacy instructors will do so as well.

Fifth, differences in grading approaches complicate interpretations of grades. Many instructors use examinations to assess learning. Examinations tend to reflect performance, but performance may reflect acute studying more so than learning. There is sufficient evidence that acute examination performances may not reflect longer-term retention ${ }^{9-13}$ For example, student A scores $90 \%$ on an examination and student B scores $85 \%$. The interpretation is that Student A learned more than B. However, the interpretation might change if a surprise repeat examination is administered a month later and Student B outperforms Student A. Traditional approaches to grading usually do not consider growth over time and the impact and importance of longitudinal growth. The complexity of grade interpretation is illustrated by comparing students with different trajectories of learning. For example, a student who starts the semester with low scores but progressively improves over time to achieving the best grades in the class will finish with the same grade as a student with a mirror opposite performance.

Overall, grades may reflect aspects of learning, but may not be a particularly accurate measure. Interpretations of grades within and across systems are clouded by numerous issues of instructor variability, which brings into question the validity and usefulness of grades for sorting students by their learning outcomes.

\section{Do Classroom Grades Align with Clinical Performance?}

Correlations between didactic training and clinical performance have become increasingly critical as accreditation standards continue to emphasize the readiness of students to enter advanced pharmacy practice experiences (APPEs). The interface between grades and experiential coursework traverses two issues. First, investigators have raised the issue of whether performance within the didactic curriculum (as measured by grades) correlates to performance in clinical settings. ${ }^{14-16}$ Second, some have questioned whether in clinical settings if Pass/Fail grading systems might be more logical as compared to traditional A-F grading scales. ${ }^{17-20}$

Call and colleagues aimed to determine factors predictive of student failure or poor performance on APPEs by conducting a retrospective cohort study comparing students who failed any APPE to students who did not between 2012$2014 .{ }^{14}$ A total of 669 students at a single pharmacy school were included in the analysis with 28 students $(4.2 \%)$ failing 
at least one APPE, and 81 students (12.1\%) being labeled as poor performers (grade of C or F). Poor academic performance and/or an identified professionalism issue while completing an introductory pharmacy practice experience (IPPE) were associated with both failure and poor APPE performance. Nyman and colleagues attempted to determine predictors of student readiness for APPEs by developing a predictive model that included 23 covariates. ${ }^{16}$ Two hundred and twenty-six students from a single college between 2015 and 2018 were included in the analysis. Grade point average within pharmacy curriculum core courses was the strongest predictor of performance. Total score on the Pharmacy Curriculum Outcomes Assessment (PCOA) was a modest yet consistent predictor of performance, defined by APPE midpoint and final scores. McLaughlin and colleagues examined the relationship between admissions data, Objective Structured Clinical Examination (OSCE) scores, and APPE performance in a cohort of PharmD students at a single college of pharmacy. ${ }^{15}$ The investigators reported that associations between all three variables and APPE scores were weak with the strongest being final OSCE scores. Low performers on the final OSCE performed worse than others on specific APPEs (acute care, ambulatory care, community). The researchers concluded that the complexities of assessing students and in turn predicting performance in the clinical arena are complex and likely a mixture of both cognitive and non-cognitive factors.

For a myriad of reasons, some health professions programs have moved to pass/fail grading of some didactic as well as experiential coursework. ${ }^{19}$ The advent and increased use of OSCEs as components of assessment has in some instances helped bridge the gap between pass/fail and traditional grading systems. Medical schools began investigating the prospects of pass/fail grading as early as the late 1960s when concerns arose that students were achieving for the sole purposes of earning certain grades rather than for the sake of learning. ${ }^{17}$ Pass/fail grading was hypothesized to be able to better identify students who would be motivated to learn and achieve even in the absence of grades. Movement in this direction was also supported by research results that did not demonstrate correlations between traditional grades and clinical performance, but did report decreases in competition among students. ${ }^{18,20}$

\section{How do Grades Affect Motivation?}

One common sentiment among instructors is that grades motivate students to learn and that students may ignore any activity that does not have a direct link to their grade. In some cases, points may be used to incentivize behavior more so than measure learning. Grades $d o$ influence which tasks students complete, but the motivational nature of grades is more complicated and nuanced, with several reasons why this is problematic.

Motivation is a complex construct that can be examined from a variety of perspectives and theoretical models. However, at the most basic level, motivation can be described as being either intrinsic or extrinsic. Students with an intrinsic motivation will complete learning activities out of a natural curiosity and desire to obtain knowledge and skills. Those with extrinsic motivation engage in activities for some external reward (eg, getting a good grade or pleasing the instructor) rather than an internal desire to learn. ${ }^{21}$ Extrinsic motivation is on display when students plead for partial credit points. Intrinsic motivation drives student behavior to learn for the sake of learning, not because there is some reward for doing so. With grades as an external motivator, students may still learn and devote appropriate attention if they selfendorse the value of the activities beyond the grade; however, decades of research have shown that the use of external rewards to motivate learning is much less powerful than intrinsic motivation. ${ }^{21}$

The most significant problem with grades as an external motivator is not that they fail to motivate students, but the psychological effects they exert. Grades can motivate students, but in the wrong way for the wrong reasons. In many cases grades can have a negative effect on the more desirable intrinsic motivation. Results of Deci and colleagues' metaanalysis of 128 studies showed that tangible rewards (eg, grades, points, etc.) undermined intrinsic motivation across a variety of activities. ${ }^{22}$ When grades are introduced the internal drive to engage in learning may be replaced with the desire to achieve the external reward. ${ }^{23}$ In economics theory, this is called the "crowding out" effect, which means that the introduction of external rewards pushes away intrinsic motivation. ${ }^{24}$ It is a subtle, but notable switch. The result of using grades to incentivize student behaviors is that it may lead to gamesmanship - with students focusing more on obtaining points and desired grades instead of maximizing learning. ${ }^{25}$

\section{Are Grades a Good Form of Feedback?}

In traditional education settings, students typically receive one of two different types of feedback on their work or assessments: evaluative or descriptive. ${ }^{26}$ Grades are a form of evaluative feedback, which tells learners how they compare to others and provides a judgment summarizing the quality of learning or characteristics of the learner. ${ }^{27}$ Evaluative feedback consists of letter grades, points, or percentage marks and can even include statements of praise or concern such as "try harder next time", "your skills have improved" or "good work". ${ }^{27}$ In contrast, descriptive feedback focuses on depicting the characteristics of the work product in order to help students understand how to improve academic 
knowledge and performance for future assessments. ${ }^{27}$ One example of descriptive feedback regarding a student's communication skills is "you made some mistakes with the use of open-ended questions, in the future make sure you ask "what questions do you have about your medication versus 'do you have any questions?"”

As a form of evaluative feedback, grades can interfere with learning. Lipnevich and Smith demonstrated that including a grade with descriptive feedback depressed future learning performance versus providing descriptive feedback alone. ${ }^{26}$ Koenka and colleague's meta-analysis of the impact of grades on learning showed that compared to written feedback and no feedback at all, students receiving grades had poorer achievement and less optimal motivation. ${ }^{28}$ Therefore, simply telling students their test grade or indicating which questions they missed does not help improve their knowledge or skills as much as providing feedback about why a certain answer is correct or incorrect.

Even descriptive feedback is meaningless though, if students only passively review it or do not read it at all. Research has shown that although students want feedback, they may not engage with it (such as not read it or forget it), reflect on it, or interpret or apply it. ${ }^{29-31}$ Grades may contribute to this problem as well. As Keupper-Tetzel and colleagues showed, the presence of a grade can interfere with students' engagement with feedback, because students may prioritize and focus on the grade versus processing and attending to written descriptive feedback. Engagement with feedback and future academic performance were improved when feedback was given before the grade was released compared to groups who received their grade followed by feedback. ${ }^{32}$ Therefore, in order for feedback to be used effectively to improve performance, it must encourage the student to be "mindful" when responding ${ }^{33}$ and it must move the learner to actively process the information. ${ }^{34}$ Grades do not appear to stimulate either of these situations.

\section{DISCUSSION}

The evidence surrounding use of traditional, multi-tiered grading systems suggests that we need to move away from them and toward practices that are more valid and reliable. However, before recommending widespread grading reform, it is important to recognize the difficulties associated with such a change.

\section{Barriers to Revising Grading Practices}

Barriers to reforming grading practices are philosophical, cultural, and logistical in nature and exist at an Academy level as well as with individual instructors. One of the longstanding concerns with regard to changing grading systems at a programmatic level is the potential effect on how residency and/or other post-graduate programs evaluate candidates. ${ }^{35}$ As postgraduate experiences such as residencies and fellowships becoming increasingly popular and competitive, the need to discriminate between candidates has become increasingly relevant. In a 2015 study of 4056 graduating pharmacy students, Caballero and colleagues showed that those with an alpha-numeric grading scale were $5.9 \%$ more likely to match with a residency than students from a pass-fail grading system. ${ }^{36}$ Critics of non-traditional grading systems have argued that in the absence of a traditional grading scale, discrimination between passing students becomes arduous if not impossible. ${ }^{19}$ However, sentiments about using grades as a primary determinant of residency suitability may be changing. It can be argued that the purpose of sorting and discriminating candidates is not the purpose of academic programs, but rather of employers. Several pharmacy educators, citing the flaws of grading and grade point averages (GPAs) that were outlined previously, advocate that GPAs are a poor tool for screening residency candidates. ${ }^{37,38}$ Pincus and colleagues examined the effects of letter grade versus pass/fail grading on pharmacy residency match rates between 2013 and $2015 .{ }^{39}$ One hundred schools were included in the analysis, which found higher match rates in the pass/fail (versus traditional grades) cohort in 2013 but no subsequent differences in 2014 and 2015. The authors hypothesized that in some instances letter grades may actually harm applicants by calling attention to lower performance.

Another big challenge to grading reform is the time, expertise, and resources required to develop and implement practices that overcome the shortcomings of grades mentioned throughout this paper. Most faculty have not been adequately trained in the complexity and nuances of how to measure learning, provide evaluative feedback, and motivate students to learn without the use of points or grades. For example, assessing learning via competency demonstrations (eg, OSCEs) requires skill in case development and can be logistically time-consuming and expensive to implement on a wide scale. Even with more traditional forms of testing, creating assessments that are true measures of learning requires expert knowledge in item construction, sampling, and test development. Furthermore, when attempting to measure medical competence, applying numerical scores gets increasingly difficult as these assessments incorporate not just knowledge, but also personality traits, skills, attitudes, and problem-solving ability. ${ }^{40}$

A hurdle to eliminating the use of points and grades for motivation is that they have been a proven method to compel students to complete activities. Designing instructional practices that incentivize students to try, fail, study, and learn - not just put forth token effort is challenging. It may be difficult for instructors to imagine alternative ways to motivate and seem like too much of a risk to take, especially if an instructor is alone in their attempts to eschew grades as 
motivators. At least initially, some students may choose to continue "gaming" the educational system by focusing more on classes that do use grades to incentivize behavior. Finally, like the challenge of designing valid learner assessments mentioned above, it can take significant amounts of time and effort to change a familiar grading system to one that accurately reflects competency as opposed to learner behaviors.

With regard to providing learners feedback through means other than points or grades, time and expertise are constraints once again. Descriptive feedback increases the time instructors spend on assessment and it may take extensive effort and support to overhaul a programmatic system that has relied on evaluative feedback. Finally, separating the feedback component from grades themselves, so that students focus only on the feedback may also be a cultural shift for both faculty and students.

\section{Recommendations for Revising Grading}

Despite the challenges mentioned previously, the Academy should examine, purposely re-design, and implement grading practices in ways that are more evidence-based and less reliant on historical tradition. To improve upon the shortcomings of how we often use grades, the Academy should consider the following recommendations (Table 2).

First, colleges and schools should consider what elements of their curricula, from didactic to clinical, could be transitioned from multi-tiered grading systems to pass/fail scales. Traditional tiered grading systems may fail to accurately discriminate authentic learning and in turn produce flawed rankings of students. Foregoing tiered grading for a competency-based or pass/fail grading systems has added benefits for improving intrinsic motivation and overcoming student focus on "chasing points." 11,42 In these types of systems, students must simply prove they meet pre-defined learning objectives as opposed to striving for the external reward of a particular grade. Common concerns that pass/fail and similar grading systems set a "low bar" can easily be overcome by defining stringent criteria and setting the threshold as high as necessary to ensure that students who pass have achieved the necessary skills and knowledge outcomes. This means that a pass standard need not necessarily be linked to an equivalent score of D $(60 \%)$. There is sufficient evidence within health professions and pharmacy education to suggest that removal of tiered grading generally does not reduce motivation or performance. ${ }^{19,42-45}$ Students who learn in environments focused on mastery versus competing for grades exhibit higher levels of motivation and achieve greater learning outcomes. ${ }^{46}$ This type of grading system also has the added benefit of increasing various forms of personal well-being ${ }^{19,47}$ because it reduces competition, encourages collaboration, and promotes self-regulation. ${ }^{42}$

Second, assessment of clinical skills should be based upon entrustable professional activities (EPAs) rather than points-based grades. Quantitative scores in clinical settings are limited in that they are often anchored and weighted on unknown or ambiguous factors. EPAs are a more holistic method of assessment that likely reflect clinical skills more precisely and authentically than do quantitative scores. Assessing students against EPA attainment levels may also provide more information to postgraduate programs (e.g., residency programs) and potential employers.

Third, when it is appropriate to use exams, they should be created through blue-printing, sufficient sampling, and careful item-writing. Test blue-printing is a systematic process to create valid exams by matching and linking test items with content delivered during instruction. ${ }^{48}$ Best practices for test blueprinting suggest the relative weighting of items should depend on importance, such as frequency, urgency, or impact of the topic. For example, hyperkalemia which may be common and life-threatening may garner more weighting than alkalosis which is less common and serious but not life threatening as compared to even less weighting for polyuria which is rarely seen and non-urgent. ${ }^{49}$ To the point of not burdening students with over-assessment, the more sampling that can be accomplished, the more valid our interpretations of achievement become. Attention should be given to individual questions to ensure validity and reflect the intended competency. Recognizing resource limitations, the increased use of OSCEs as a means of assessment should be encouraged, as they may provide a more accurate assessment of a student's ability to perform the functions of a pharmacist.

Fourth, grades should be used solely for the purposes of assessing learning versus incentivizing students to attend class, participate in class activities, or engage in other competency-developing behaviors. As stated earlier, when grades are used as motivators, student focus turns away from learning and toward obtaining the points. Instead of using grades as an external reward to motivate students, we should focus more on cultivating intrinsic motivation. Instructors should find ways to provoke curiosity, provide autonomy, model enthusiasm, and emphasize that the goal is content mastery to optimize health of patients. ${ }^{50}$

Fifth, grades should be separated from feedback and that feedback should be descriptive rather than evaluative. When grades and feedback are paired, students may pay less attention to the feedback because of the focus on grades. Even in programs where quantitative or tiered grading systems remain the only option, faculty can still frame courses so that students are provided constructive feedback and where credit is earned through continual improvement and editing of 
assignments and test material. This emphasis on continued professional development can help move the focus from numeric grades to learning products and tangible outcomes. In situations where grades must be provided to students, providing feedback first and temporarily withholding those grades generally results in better outcomes than providing grades and feedback simultaneously. Although research literature does not provide best-practices with regard to timing of sequencing, the important factor is that students are forced to engage with the feedback before receiving the grade. ${ }^{32}$

Finally, inherent challenges to widespread change exist as various programs across the Academy utilize different assessment and grading methods. These differences are not only a barrier to reform, but also make it problematic for employers to interpret. The Academy should consider hosting conversations and workshops combining pharmacy faculty and employer stakeholders to bring greater awareness of grading systems, their effects on learning, and what employers desire and use with regard to interpreting learner competence. Workshops should include training and guidance on how to effectively create and utilize evidence-based grading practices that are superior to traditional points-based, tiered grading for measuring learning, motivating students, and providing feedback.

\section{CONCLUSION}

There is sufficient evidence to show that traditional grading systems do a relatively poor job of accurately measuring knowledge and clinical skills, motivating students, and providing feedback. Despite barriers and potential pushback from some faculty, students, and employers, programs need to consider the evidence and revise grading systems to meet several criteria. While there is no single ideal way to approach grades, a good grading system should uphold high academic standards; accurately reflect student learning outcomes/competencies; motivate students to learn; reduce undue student stress; make students feel responsible for their learning; minimize conflict between faculty and students; and give students feedback they will use.

\section{ACKNOWLEDGEMENTS}

We thank Dr. Tina Brock for her constructive feedback on the initial draft of this manuscript.

\section{REFERENCES}

1. Supiano B. Grades can hinder learning: What should professors use instead. Chron Higher Educ. 2019.

2. Katoue MG, Schwinghammer TL. Competency-based education in pharmacy: A review of its development, applications, and challenges. J Eval Clin Pract. 2020;26(4):1114-1123.

3. Nilson LB. Specifications grading: Restoring rigor, motivating students, and saving faculty time. Stylus Publishing, LLC; 2015.

4. $\quad$ Blum SD, Kohn A. Ungrading: Why Rating Students Undermines Learning (and What to Do Instead). Morganown: West Virginia University Press; 2020.

5. Schneider J, Hutt E. Making the grade: A history of the A-F marking scheme. J Curric Stud. 2014;46(2):201-224.

6. $\quad$ Deddeh H, Main E, Fulkerson SR. Eight steps to meaningful grading. Phi Delta Kappan. 2010;91(7):53-58.

7. Donaldson JH, Gray M. Systematic review of grading practice: Is there evidence of grade inflation? Nurs Educ Pract. 2012;12(2):101-114.

8. Biberman-Shalev L, Sabbagh C, Resh N, Kramarski B. Grading styles and disciplinary expertise: The mediating role of the teacher's perception of the subject matter. Teach. 2011;27(5):831-840.

9. Conway MA, Cohen G, Stanhope N. On the very long-term retention of knowledge acquired through formal education: Twelve years of cognitive psychology. J Exp Psychol Gen. 1991;120(4):395-409.

10. Conway MA, Cohen G, Stanhope N. Why is it that University grades do not predict very-long-term tetention? $J$ Exp Psychol Gen. 1992;121(3):382-384.

11. Custers EJFM, Custers EJFM. Long-term retention of basic science knowledge: A review study. Adv Health Sci Educ: Theory Pract. 2010;15(1):109-128.

12. Persky AM, Wells MA, Sanders KA, Fiordalisi J, Downey C, Anksorus HN. Improving dental students' long-term retention of pharmacy knowledge with "medication minutes". J Dent Educ. 2017;81(9):1077-1084.

13. Terenyi J, Anksorus H, Persky AM. Optimizing the spacing of retrieval practice to improve pharmacy students' learning of drug names. Am J Pharm Educ. 2019;83(6):Article 7029.

14. Call WB, Grice GR, Tellor KB, Armbruster AL, Spurlock AM, Berry TM. Predictors of student failure or poor performance on advanced pharmacy practice experiences. Am J Pharm Educ. 2020;84(10):Article 7890.

15. McLaughlin JE, Khanova J, Scolaro K, Rodgers PT, Cox WC. Limited predictive utility of admissions scores and objective structured clinical examinations for APPE performance. Am J Pharm Educ. 2015;79(6):Article 84. 
16. Nyman H, Moorman K, Tak C, Gurgle H, Henchey C, Munger MA. A modeling exercise to identify predictors of student readiness for advanced pharmacy practice experiences. Am J Pharm Educ. 2020;84(5):Article 7783.

17. Dietrick JA, Weaver MT, Merrick HW. Pass/fail grading: A disadvantage for students applying for residency. Am J Surg. 1991;162(1):63-66.

18. Korman M, Stubblefield RL. Medical school evaluation and internship performance. Acad Med. 1971;46(8):670673.

19. Spring L, Robillard D, Gehlbach L, Moore Simas TA. Impact of pass/fail grading on medical students' well-being and academic outcomes. Med Educ. 2011;45(9):867-877.

20. Wingard JR, Williamson JW. Grades as predictors of physicians' career performance: an evaluative literature review. Acad Med. 1973;48(4):311-322.

21. Ryan RM, Deci EL. Intrinsic and extrinsic motivations: Classic definitions and new directions. Contemp Educ Psychol. 2000;25(1):54-67.

22. Deci EL, Koestner R, Ryan RM. Extrinsic rewards and intrinsic motivation in education: Reconsidered once again. Rev Educ Res. 2001;71(1):1-27.

23. Pulfrey C, Darnon C, Butera F. Autonomy and task performance: Explaining the impact of grades on intrinsic motivation. J Educ Psychol. 2013;105(1):39-57.

24. Frey BS. How intrinsic motivation is crowded out and in. Ration Soc. 1994;6(3):334-352.

25. Cain J. School is a game: Faculty set the rules. Currents Pharm Teach Learn. 2017;9(3):341-343.

26. Lipnevich AA, Smith JK. Effects of differential feedback on students' examination performance. J Exper PsychApplied. 2009;15(4):319-333.

27. Feedback in practice: Evaluative and descriptive. https://www.moedu-sail.org/lessons/evaluative-descriptivefeedback/. Accessed October 18, 2021.

28. Koenka AC, Linnenbrink-Garcia L, Moshontz H, Atkinson KM, Sanchez CE, Cooper H. A meta-analysis on the impact of grades and comments on academic motivation and achievement: a case for written feedback. $E d u c$ Psychol. 2021;41(7):922-947.

29. Ali N, Ahmed L, Rose S. Identifying predictors of students' perception of and engagement with assessment feedback. Active Learn Higher Educ. 2018;19(3):239-251.

30. Price M, Handley K, Millar J. Feedback: Focusing attention on engagement. Studies Higher Educ. 2011;36(8):879-896.

31. Duncan N. Improving students' use of tutors' comments. Assess Eval Higher Educ. 2007;32(3):271-283.

32. Keupper-Tetzel C, Gardner P. Effects of temporary mark withholding on academic performance. Psych Learn Teach. 2021:1-15.

33. Bangert-Drowns R, Kulik J, Morgan M. The instructional effect of feedback in test-like events. Rev Educ Res. 1991;61:213-238.

34. Hattie J, Timperley H. The power of feedback. Rev Educ Res. 2007;77:81-113.

35. Son E, Ding K, Nejim I, Brock TP. Preferences for grading systems amongst pharmacy residency directors. Cal $J$ Health Syst Pharm. 2016;28(1):22-32.

36. Caballero J, Benavides S, Clauson KA, Hardigan PC, Martinez BK, Llerena V. Non-modifiable determinants of pharmacy residency match rates. Int J Pharm Pract. 2017;26(1):81-84.

37. Soric MM, Robinson JD, Ulbrich TR. Grade point average is an inappropriate measure of a residency candidate's knowledge and skills. J Am Coll Clin Pharm. 2019;2(2):177-180.

38. Jungnickel PW. Grade-point averages and class rankings in evaluation of pharmacy residency applicants. Am J Health Syst Pharm. 2010;67(18):1500-1502.

39. Pincus K, Hammond A-D, Reed BN, Feemster AA. Effect of advanced pharmacy practice experience grading scheme on residency match rates. Am J Pharm Educ. 2019;83(4):Article 6735.

40. Schuwirth LW, van der Vleuten CP. A history of assessment in medical education. Adv Health Sci Educ. 2020;25(5):1045-1056.

41. Ramaswamy V, Veremis B, Nalliah RP. Making the case for pass-fail grading in dental education. Eur J Dent Educ. 2020;24(3):601-604.

42. White CB, Fantone JC. Pass-fail grading: laying the foundation for self-regulated learning. Adv Health Sci Educ. 2010;15(4):469-477.

43. Ange B, Wood EA, Thomas A, Wallach PM. Differences in medical students' academic performance between a pass/fail and tiered grading system. South Med J. 2018;111(11):683-687. 
44. Chamberlin K, Yasué M, Chiang I-CA. The impact of grades on student motivation. Active Learn Higher Educ. 2018: doi:1469787418819728.

45. Manning DH, Ference KA, Welch AC, Holt-Macey M. Development and implementation of pass/fail grading system for advanced pharmacy practice experiences. Currents Pharm Teach Learn. 2016;8(1):59-68.

46. Meece JL, Anderman EM, Anderman LH. Classroom goal structure, student motivation, and academic achievement. Annu Rev Psychol. 2006;57:487-503.

47. Reed DA, Shanafelt TD, Satele DW, et al. Relationship of pass/fail grading and curriculum structure with wellbeing among preclinical medical students: A multi-institutional study. Acad Med. 2011;86(11):1367-1373.

48. Bridge PD, Musial J, Frank R, Roe T, Sawilowsky S. Measurement practices: Methods for developing contentvalid student examinations. Med Teach. 2003;25(4):414-421.

49. Coderre S, Woloschuk W, McLaughlin K. Twelve tips for blueprinting. Med Teach. 2009;31(4):322-324.

50. Lyons KM, Cain JJ, Haines ST, Gasevic D, Brock TP. The clinical educator's guide to fostering learner motivation: AMEE Guide No. 137. Med Teach. 2020:1-9. 
Figure 1. Ability of an Assessment to Differentiate Between Two Grades Based on Exam Reliability and Variability

$$
\begin{aligned}
& \underline{\text { Condition }} \\
& K R 20=.9 ; S D=10 \\
& K R 20=.9 ; S D=10 \\
& K R 20=.6 ; S D=10 \\
& K R 20=.6 ; S D=10 \\
& K R 20=.9 ; S D=20 \\
& K R 20=.9 ; S D=20 \\
& K R 20=.6 ; S D=20 \\
& K R 20=.6 ; S D=20
\end{aligned}
$$

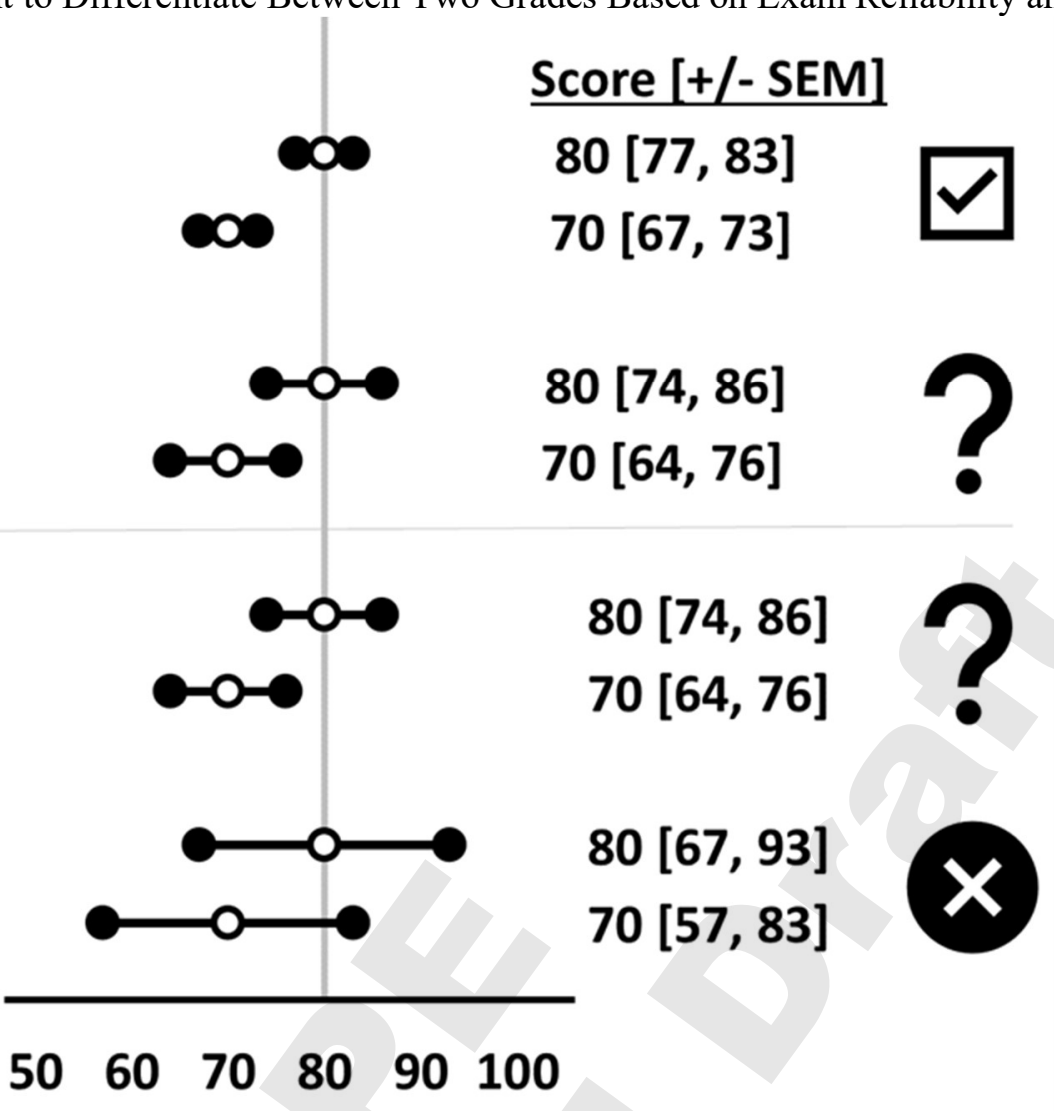


Table 1. How Grades can Differ Depending on the Grading Scheme Used ${ }^{6}$

\begin{tabular}{lllllll}
\hline & & & & $\begin{array}{l}\text { Traditional } \\
\text { Grading }\end{array}$ & $\begin{array}{l}\text { Standards Based } \\
\text { Grading }\end{array}$ \\
\hline Student & Participation & Homework & Midterms & Final & $\begin{array}{l}\text { Participation: } 20 \% \\
\text { Homework: } 25 \%\end{array}$ & $\begin{array}{l}\text { Participation: } 0 \% \\
\text { Homework: } 0 \%\end{array}$ \\
& & & & $\begin{array}{l}\text { Midterm: } 25 \% \\
\text { Midterm: } 50 \%\end{array}$ \\
& & & & & Final: $30 \%$ & Final: $50 \%$ \\
A & $100 \%$ & $100 \%$ & $76 \%$ & $88 \%$ & $89 \%(\mathrm{~B})$ & $83 \%(\mathrm{~B})$ \\
$\mathrm{B}$ & $40 \%$ & $40 \%$ & $84 \%$ & $96 \%$ & $73 \%(\mathrm{C})$ & $91 \%(\mathrm{~A})$ \\
$\mathrm{C}$ & $90 \%$ & $98 \%$ & $83 \%$ & $90 \%$ & $90 \%(\mathrm{~A})$ & $87 \%(\mathrm{~B})$ \\
\hline
\end{tabular}

Table 2. Summary of Issues with Traditional Grading Systems and Recommendations for Reform

\begin{tabular}{l}
\hline Issue with traditional grading \\
\hline Grades often contain information \\
(eg, attendance) other than \\
achievement of learning objectives, \\
which diminishes accuracy \\
Grades are an imprecise measure of \\
learning
\end{tabular}
Recommendation

Use only exams and skills assessment to assess intended learning outcomes. Do not award points for items that merely facilitate the achievement of intended learning outcomes (eg, homework or participation)

Consider pass-fail grading with high standards, especially on APPE

Consider using a mastery learning approach

Base assessments on blueprinting

Pay close attention to item-writing

Use an adequate sample of questions per intended learning outcome

Tiered grading can create an adversarial relationship between faculty and students

Use a competency-based grading system with set criteria for assessing competency.

Create a remediation or corrective pathway so all students can achieve the intended learning outcomes

Traditional grading may not

Use performance-based exams and/or progression exams accurately predict clinical performance

Use a different grading scale such as Entrustable Professional Activities, which assesses the whole student (their knowledge, skills, attitudes, etc.), especially for clinical skills and attitudes

Grades are an external motivator Utilize instructional practices that promote intrinsic motivation including that hinder intrinsic motivation to learn enhancing curiosity and relevance to practice.

Consider alternative competency-based or pass-fail grading. Avoid normative grading and use more criterion-based grading

Grades, as an evaluative form of feedback, are less effective at Separate grades from feedback Offer more descriptive feedback. improving learning than descriptive feedback

Offer more sampling of knowledge opportunities, but avoid assessment fatigue 